\title{
PD-1/PD-L1 antibodies efficacy and safety versus docetaxel monotherapy in advanced NSCLC patients after first-line treatment option: systems assessment
}

\author{
Qiang Su${ }^{1}$, Zhigang Sun², Chenguang Zhang ${ }^{3}$, Yanli Hou ${ }^{4}$ and Bangwei Cao ${ }^{1}$ \\ ${ }^{1}$ Department of Oncology, Beijing Friendship Hospital, Capital Medical University, Beijing, China \\ 2 Department of Thoracic Surgery, Jinan Center Hospital Affiliated to Shandong University, Shandong University, Jinan, China \\ 3 Department of Biochemistry and Molecular Biology, School of Basic Medical Sciences, Capital Medical University, Beijing, \\ China \\ ${ }^{4}$ Department of Ophthalmology, Beijing Friendship Hospital, Capital Medical University, Beijing, China \\ Correspondence to: Yanli Hou, email: and hyl_0730@126.com
}

Bangwei Cao, email: oncology@ccmu.edu.cn

Keywords: NSCLC, PD-1 antibody, PD-L1 antibody, docetaxel, meta analysis

Received: March 06, $2017 \quad$ Accepted: July 12, $2017 \quad$ Published: July 27, 2017

Copyright: Su et al. This is an open-access article distributed under the terms of the Creative Commons Attribution License 3.0 (CC BY 3.0), which permits unrestricted use, distribution, and reproduction in any medium, provided the original author and source are credited.

\section{ABSTRACT}

Meta-analysis was conducted to systematically assess the effectiveness and safety of programmed cell death protein-1 or ligand-1 (PD-1 or PD-L1) antibodies versus docetaxel alone in advanced non small cell lung cancer (NSCLC). In addition, the prognostic significance of PD-L1 expression in advanced NSCLC was also investigated. 5 eligible studies including 3579 patients were identified through comprehensive search of multiple databases. The results showed that pooled hazard ratios (HR) for overall survival (OS) and progression free survival (PFS) were 0.69 (95\% CI: $0.63-0.75 ; p<0.001)$ and 0.87 (95\% CI: 0.80-0.94; $p<0.001)$, between PD-1/ PD-L1 antibodies and docetaxel treatment arms, respectively. The pooled relative risk (RR) value for objective response rate (ORR) was 1.53, (95\% CI: 1.16-2.01, $p=0.003$ ). Further, subgroup analysis based on PD-L1 expression indicated that pooled HR for OS was significant with 0.66 (95\% CI: 0.59-0.74, $p<0.001$ ) for PDL1 $\geq 1 \%$. However, PD-L1 < $1 \%$ had HR value of 0.79 (95\% CI: $0.67-0.93, p=0.006)$. Our study concluded that advanced NSCLC patients benefited more with PD-1/PD-L1 antibodies than docetaxel in the second line treatment. PD-L1 $\geq 10 \%$ in tumor tissues is sufficient to show significant improvement in patient's outcome with PD-1/PDL1 antibodies compared to docetaxel. Moreover, PD-1/PD-L1 antibodies treatment showed significant decrease in conventional chemotherapy adverse events, but increased immune-associated adverse effects.

\section{INTRODUCTION}

Lung cancer ranks first in term of causing cancer associated deaths worldwide, with an estimation of 221,200 new cases and 158,040 deaths alone in the year 2015 [1]. In United States, it accounts for $27 \%$ of all cancer related deaths in males, and $26 \%$ in females during the year 2016 [2], while in China, this is not only the most commonly diagnosed cancer and but also is the leading cause of cancer related deaths especially in men aged 75 years or older, and in women 60 years or older [3]. Lung cancer is usually classified into small cell lung cancer $(15 \%)$ and non-small cell lung cancer (NSCLC) $(85 \%)$. The NSCLC type has been further classified into non- squamous (NSQ) or squamous (SQ), and approximately $70 \%$ of the patients harbor a non-squamous histology. The NSQ subtype has further been categorized into adenocarcinoma (ADC), large cell carcinoma and adeno squamous carcinoma subgroups [4, 5]. Effective treatment options for NSCLC are still required due to very little progress in this direction since the approval of docetaxel as a second-line treatment in 1999 [6]. At present, targeted therapies such as tyrosine kinase inhibitors (TKI), antibodies against epidermal growth factor receptor (EGFR), inhibitors for anaplastic lymphoma kinase (ALK), and chemotherapy with platinum-based doublets have been the choice for first line treatment of advanced NSCLC. In addition, the docetaxel, a specific 
inhibitor of metaphase step in the cell cycle, has been a classic second-line therapeutic option [6-8]. However, in recent years, the development of immune checkpoint inhibitors have changed the treatment paradigm of advanced NSCLC. Recent studies have clearly revealed the mechanistic insight about the role of these checkpoint inhibitors as tumor suppressive targets. In peripheral tissues, the adaptive immune responses against tumor cells is negatively regulated, in part by binding of activated T cells expressing PD-1 with the PD-L1 and/or PD-L2 on tumor cells [8]. This, upregulated expression of PDL1 on tumor cells helps to evade immune response [9], by inhibiting the T-cell responses and leads to immune resistance [10]. Thus, PD-1 and PD-L1 inhibitors/ antibodies have been able to restore the $\mathrm{T}$ cells function in peripheral tissues by blocking the direct binding of $\mathrm{T}$ cell expressing PD-1 with PD-L1 or PD-L2 on tumor cells [10, 11]. In 2015, two PD-1 inhibitors/antibodies (nivolumab and pembrolizumab) have received US Food and Drug Administration (FDA) approval for the use in advanced NSCLC after platinum-based chemotherapy. Nivolumab has been recommended for patients with SQ-NSCLC and NSQ-NSCLC, while pembrolizumab for NSCLC tumors expressing PD-L1 [11-13].

Apparently the cost of immunotherapy for advanced NSCLC has been enormous [14] and is difficult for many patients in different countries to bear this cost. Therefore, an effective and less expensive treatment strategy is required to guide the application of immune checkpoint inhibitors/antibodies. There have been some studies indicating that PD-L1 expression level can serve as a biomarker for PD-1/PD-L1 antibodies based immunotherapy in NSCLC [15-20]. But there is an ambiguity in terms of PD-L1 expression being a suitable marker for PD-1/PD-L1 antibodies treatment for advanced NSCLC compared with docetaxel in the second-line treatment. To address this issue, we conducted a metaanalysis of randomized clinical trials (RCTs) to determine the efficacy and safety of PD-1 or PD-L1 antibodies compared with standard second-line therapy docetaxel alone and to assess the possible association between the level of PD-L1 and the prognosis of PD-1/PD-L1 antibodies in patients of advanced NSCLC.

\section{RESULTS}

\section{Selection of studies and their characteristics}

Based on the search criteria, we initially identified 1011 studies from our database search. Among these, 858 studies were excluded because they did not fit our selection criteria. Of the remaining 153 studies, only 5 randomized controlled trials (RCTs) passed the inclusion criteria, and others were excluded because of repetitive

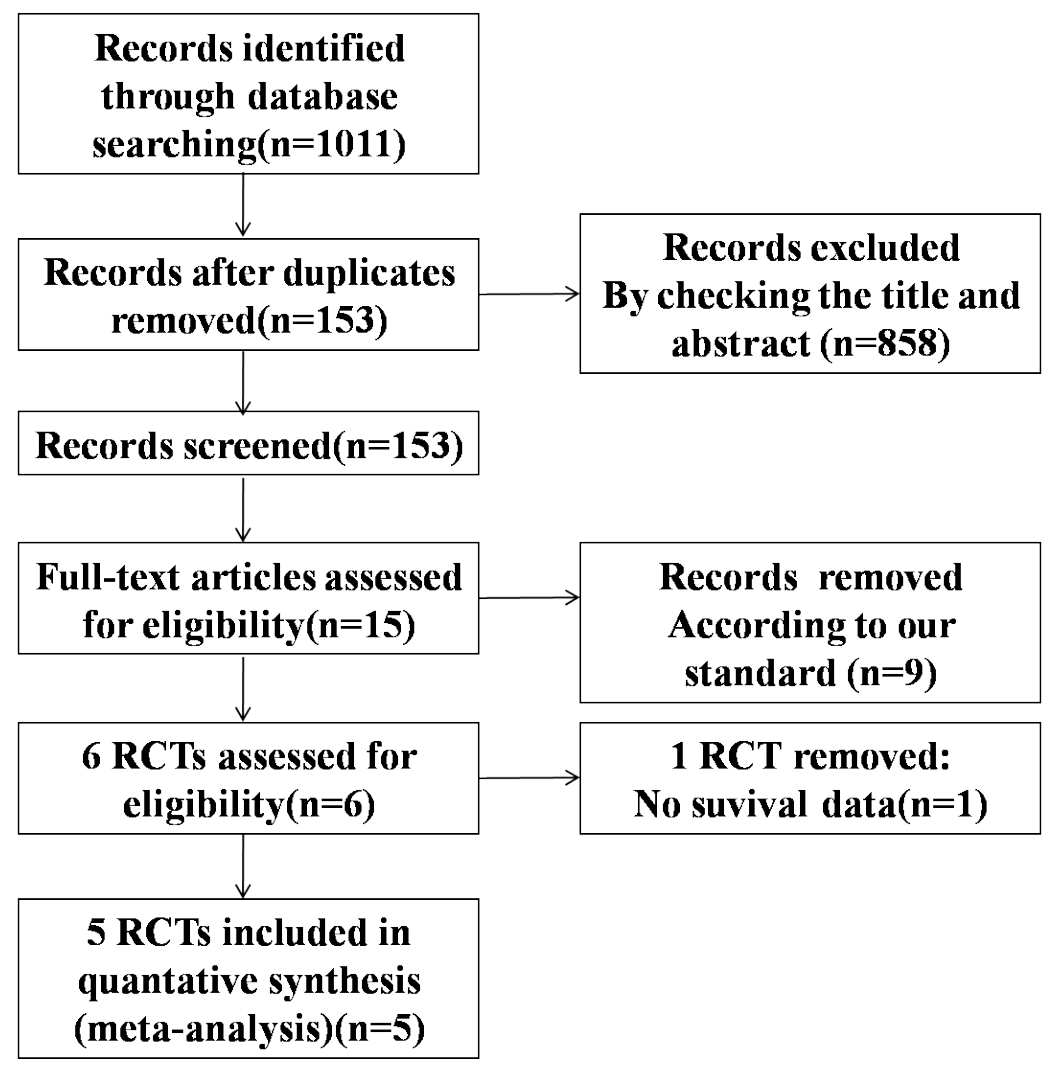

Figure 1: Flowchart depicting the RCTs selection process. 
Table 1: Characteristics of the eligible RCTs included in the meta-analysis

\begin{tabular}{|c|c|c|c|c|c|c|c|c|}
\hline study[year] & Study type & histology & endpiont & Treatment arms & Patients & CR+PR(\%) & OS(m) & PFS(m) \\
\hline \multirow[t]{2}{*}{ Borghaei et al. [2015] } & RCT III & NSQ & OS & nivolumab $3 \mathrm{mg} / \mathrm{kg}$ q2w & 292 & $56(19 \%)$ & 12.2 & 2.3 \\
\hline & & & & DOX $75 \mathrm{mg} / \mathrm{m} 2 \mathrm{q} 3 \mathrm{w}$ & 290 & $36(12 \%)$ & 9.4 & 4.2 \\
\hline \multirow[t]{2}{*}{ Brahmer et al. [2015] } & RCT III & SQ & OS & nivolumab $3 \mathrm{mg} / \mathrm{kg}$ q2w & 135 & $27(20 \%)$ & 9.2 & 3.5 \\
\hline & & & & DOX $75 \mathrm{mg} / \mathrm{m} 2 \mathrm{q} 3 \mathrm{w}$ & 137 & $12(9 \%)$ & 6.0 & 2.8 \\
\hline \multirow[t]{2}{*}{ Fehrenbacher[2016] } & RCT II & SQ and NSQ & OS & atezolizumab $1200 \mathrm{mg} \mathrm{q} 3 \mathrm{w}$ & 144 & $21(14.6 \%)$ & 12.6 & 2.7 \\
\hline & & & & DOX $75 \mathrm{mg} / \mathrm{m} 2 \mathrm{q} 3 \mathrm{w}$ & 143 & $21(14.7 \%)$ & 9.7 & 3.0 \\
\hline \multirow[t]{2}{*}{ Herbst et al. [2015]1 } & RCT III & SQ and NSQ & OS & \begin{tabular}{|rr} 
pembrolizumab & $2 \mathrm{mg} / \mathrm{kg}$ \\
$\mathrm{q} 2 \mathrm{w}$ & \\
\end{tabular} & 344 & $62(18.0 \%)$ & 10.4 & 3.9 \\
\hline & & & & DOX $75 \mathrm{mg} / \mathrm{m} 2 \mathrm{q} 3 \mathrm{w}$ & 343 & $32(9.3 \%)$ & 8.5 & 4.0 \\
\hline \multirow[t]{2}{*}{ Herbst et al. [2015]2 } & RCT III & SQ and NSQ & OS & $\begin{array}{r}\text { pembrolizumab } 10 \mathrm{mg} / \mathrm{kg} \\
\mathrm{q} 2 \mathrm{w}\end{array}$ & 346 & $64(18.5 \%)$ & 12.7 & 4.0 \\
\hline & & & & DOX $75 \mathrm{mg} / \mathrm{m} 2 \mathrm{q} 3 \mathrm{w}$ & 343 & $32(9.3 \%)$ & 8.5 & 4.0 \\
\hline \multirow[t]{2}{*}{$\begin{array}{l}\text { Rittmeyer et } \\
\text { al.[2017] }\end{array}$} & RCT II & SQ and NSQ & OS & atezolizumab $1200 \mathrm{mg} \mathrm{q} 3 \mathrm{w}$ & 425 & $58(13.6 \%)$ & 13.8 & 2.8 \\
\hline & & & & DOX $75 \mathrm{mg} / \mathrm{m} 2 \mathrm{q} 3 \mathrm{w}$ & 425 & $57(13.4 \%)$ & 9.6 & 4.0 \\
\hline
\end{tabular}

RCT: randomized controlled trials; SQ: Squamous non small cell lung cancer; NSQ: Non-squamous non small cell lung cancer; DOX: docetaxel
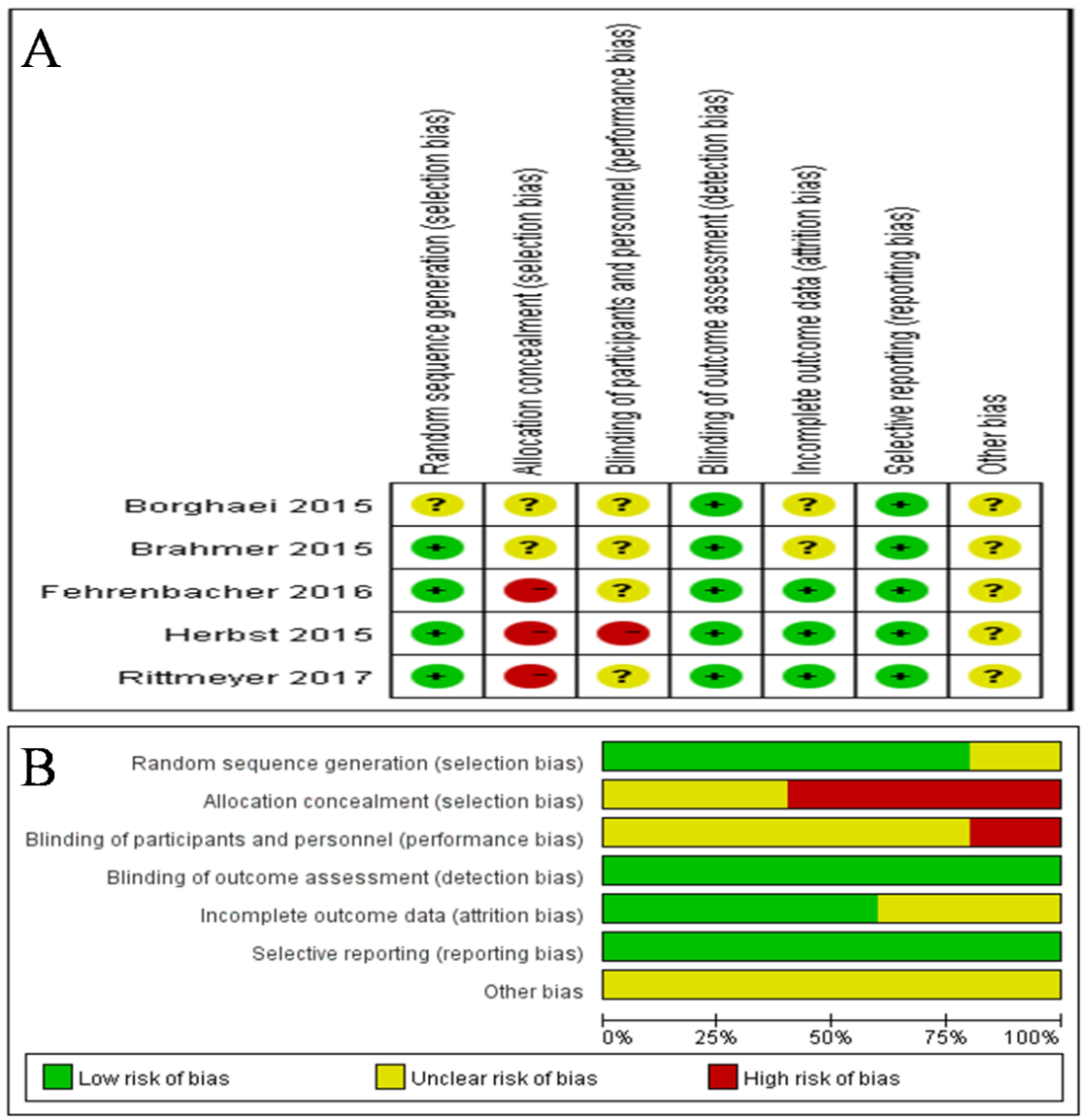

Figure 2: Risk of bias summary. A. Risk of bias for each included RCT,representing low risk of bias (+), high risk of bias (-), and unclear risk of bias (?). B. Bar chart comparing percentage risk of bias for each included RCT. Low risk of bias (Green), high risk of bias (Red), and unclear risk of bias (Yellow). 
Table 2: Treatment-Related AEs (Grade 1-4/3-4) for PD-1/PD-L1 antibodies vs. docetaxel

\begin{tabular}{|c|c|c|c|c|c|c|c|}
\hline \multirow{2}{*}{\begin{tabular}{|l} 
AEs (Grade 1-4/3-4) \\
any events(G1-4)
\end{tabular}} & \multirow{2}{*}{\begin{tabular}{|l|} 
PD1/PD-L1antibody \\
$1201 / 1851$ \\
\end{tabular}} & \multirow{2}{*}{\begin{tabular}{|l} 
DOX \\
$1464 / 1728$ \\
\end{tabular}} & \multicolumn{2}{|c|}{\begin{tabular}{|l|}
$\begin{array}{l}\text { Heterogeneity } \mathrm{P} \\
\text { and } \mathbf{I}^{\mathbf{2}}\end{array}$ \\
\end{tabular}} & \multirow{2}{*}{\begin{tabular}{|l} 
RR (95\% CI) \\
$0.77(0.74,0.79)$
\end{tabular}} & \multirow{2}{*}{ 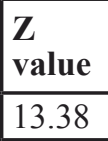 } & \multirow{2}{*}{\begin{tabular}{|l|}
$\boldsymbol{P}$ value \\
0.000 \\
\end{tabular}} \\
\hline & & & 0.421 & $0.0 \%$ & & & \\
\hline$(\mathrm{G} 3-4)$ & $284 / 1851$ & $751 / 1728$ & 0.000 & $91.0 \%$ & $0.33(0.22,0.51)$ & 5.03 & 0.000 \\
\hline Nausea(G1-4) & $239 / 1851$ & $358 / 1728$ & 0.047 & $55.0 \%$ & $0.58(0.46,0.75)$ & 4.28 & 0.000 \\
\hline (G3-4) & $10 / 1851$ & $8 / 1728$ & 0.827 & $0.0 \%$ & $0.15(0.48,2.77)$ & 0.31 & 0.756 \\
\hline $\begin{array}{l}\text { Febrile } \\
\text { neutropenia(G1-4) }\end{array}$ & $1 / 1851$ & $146 / 1728$ & 0.994 & $0.0 \%$ & $0.02(0.01,0.06)$ & 7.06 & 0.000 \\
\hline (G3-4) & $1 / 1851$ & $144 / 1728$ & 0.994 & $0.0 \%$ & $0.02(0.01,0.07)$ & 7.03 & 0.000 \\
\hline Diarrhea(G1-4) & $182 / 1851$ & $371 / 1728$ & 0.032 & $59.0 \%$ & $0.41(0.31,0.55)$ & 5.98 & 0.000 \\
\hline (G3-4) & $9 / 1851$ & $35 / 1728$ & 0.800 & $0.0 \%$ & $0.26(0.13,0.52)$ & 3.79 & 0.000 \\
\hline Neutropenia(G1-4) & $16 / 1851$ & $322 / 1728$ & 0.051 & $55.0 \%$ & $0.04(0.02,0.10)$ & 6.74 & 0.000 \\
\hline (G3-4) & $3 / 1851$ & $246 / 1728$ & 0.684 & $0.0 \%$ & $0.02(0.01,0.05)$ & 9.04 & 0.000 \\
\hline Anemia(G1-4) & $110 / 1851$ & $319 / 1728$ & 0.001 & $77.0 \%$ & $0.25(0.14,0.42)$ & 5.01 & 0.000 \\
\hline (G3-4) & $19 / 1709$ & $54 / 1593$ & 0.658 & $0.0 \%$ & $0.34(0.20,0.56)$ & 4.17 & 0.000 \\
\hline Fatigue(G1-4) & $354 / 1851$ & $524 / 1728$ & 0.225 & $28.0 \%$ & $0.63(0.56,0.71)$ & 7.65 & 0.000 \\
\hline (G3-4) & $32 / 1851$ & $72 / 1728$ & 0.281 & $20.0 \%$ & $0.42(0.28,0.63)$ & 4.17 & 0.000 \\
\hline $\operatorname{Rash}(\mathrm{G} 1-4)$ & $105 / 1100$ & $44 / 1015$ & 0.070 & $57.0 \%$ & $2.01(1.14,3.51)$ & 2.43 & 0.020 \\
\hline$(\mathrm{G} 3-4)$ & $3 / 1100$ & $2 / 1015$ & 0.540 & $0.0 \%$ & $1.17(0.31,4.42)$ & 0.24 & 0.810 \\
\hline Alopecia(G1-4) & $11 / 1851$ & $551 / 1728$ & 0.900 & $0.0 \%$ & $0.02(0.01,0.04)$ & 13.31 & $0.000-$ \\
\hline (G3-4) & $0 / 1851$ & $7 / 1728$ & 0.997 & $0.0 \%$ & $0.25(0.06,0.99)$ & 1.98 & 0.048 \\
\hline Colitis(G1-4) & $11 / 1242$ & $0 / 1150$ & 0.999 & $0.0 \%$ & $4.99(1.45,17.11)$ & 2.55 & 0.011 \\
\hline (G3-4) & $7 / 1242$ & $0 / 1150$ & 0.994 & $0.0 \%$ & $3.55(0.88,14.28)$ & 1.78 & 0.075 \\
\hline Hypothyroidism(G1-4) & $87 / 1242$ & $2 / 1150$ & 0.974 & $0.0 \%$ & $23.36(8.04-67.90)$ & 5.79 & 0.000 \\
\hline Hyperthyroidism(G1-4) & $36 / 969$ & $6 / 886$ & 0.765 & $0.0 \%$ & $5.10(2.23-11.68)$ & 3.85 & 0.000 \\
\hline Pneumonitis(G1-4) & $62 / 1242$ & $18 / 1150$ & 0.653 & $0.0 \%$ & $3.19(1.90-5.34)$ & 4.40 & 0.000 \\
\hline $\begin{array}{ll}\text { interstitial } & \text { lung } \\
\text { disease(G1-4) } & \\
\end{array}$ & $5 / 1100$ & $5 / 1015$ & 0.607 & $0.0 \%$ & $0.93(0.29-2.87)$ & 0.13 & 0.893 \\
\hline
\end{tabular}

or insufficient information (Figure 1). All the 5 included RCTs evaluated and compared the effectiveness of PD1/PD-L1 antibody therapies in advanced NSCLC over docetaxel, representing data from total of 3579 patients (Table 1 and 2). Out of this, 1851 patients were administered PD1/PD-L1 antibodies, while 1728 patients were given docetaxel. In addition, among the five studies, one had data from SQ-NSCLC patients [15], while another one had data from NSQ-NSCLC patients [16], and the remaining three studies $[17,18,19]$ had data from both SQ and NSQ NSCLC patients. The study by Herbst et al. had analyzed two dosage ( 2 and $10 \mathrm{mg} / \mathrm{kg}$ ) of pembrolizumab. Furthermore, the Cochrane risk of bias tool was used to measure the quality of the included studies, and the results are shown in Figure 2. Most of the included studies describe the detail of random sequence generation, Blinding of outcome assessment,incomplete outcome data and selective reporting. In some RCTs allocation was unmasked.Some studies did not mention allocation concealment, blinding of participants and personnel or random sequence generation. The other indexes of bias usually lacked specific description in the included clinical studies.

\section{Overall survival analysis}

The forest plot analysis of overall survival with PD-1/PD-L1 antibodies indicated better prognosis than docetaxel, in advanced NSCLC patients, as shown in Figure 3. Compared with docetaxel, we observed a significant decrease (31\%) in the risk of death in PD-1/ PD-L1 antibody group (HR 0.69, 95\% CI: 0.63-0.75, p < $0.001 ; \mathrm{I}^{2}=0 \%$ ). Further subgroup analysis of OS based on PD-L1 expression again revealed statistically significant advantage for PD-1/PD-L1 therapy as compared to docetaxel, with pooled HR values of 0.79 (95\% CI: 0.67$0.93, \mathrm{p}=0.006)$ in subgroups with PD-L1 expression of $<1 \%, 0.66$ (95\% CI: 0.59-0.74, p $<0.001)$ with PDL1 expression of $\geq 1 \%, 0.55$ (95\% CI: $0.45-0.67, \mathrm{p}<$ $0.001)$ with PD-L1 expression of $\geq 5 \%, 0.41$ (95\% CI: $0.27-0.63, p<0.001)$ with PD-L1 expression of $\geq 10 \%$, and 0.49 (95\% CI: $0.40-0.60, \mathrm{p}<0.001)$ with PD-L1 expression of $\geq 50 \%$. However, the pooled HR values were not statistically significant in subgroups with PD-L1 expression of $<5 \%$ [0.86(95\% CI: $0.61-1.23, \mathrm{p}=0.417)]$, and $<10 \%$ [0.86(95\% CI: $0.61-1.21, \mathrm{p}=0.381)]$. In 
addition, we found very little overall heterogeneity for OS in all studies $\left(\mathrm{I}^{2}=0 \%, \mathrm{p}=0.654\right)$, but the heterogeneity at the PD-L1 expression subgroup levels was different. For instance, PD-L1 expression of $\geq 1 \%, 5 \%, 10 \%, 50 \%$ and $<1 \%$, displayed $\mathrm{I}^{2}$ values of $0 \%(\mathrm{p}=0.740) ; 10.0 \%$ $(p=0.343) ; 0 \%(p=0.537) ; 0 \%(p=0.811) ; 18.5 \%(p$
$=0.298$ ).respectively, and represented less heterogeneity. However other subgroups based on PD-L1 expression like, $<5 \%$ and $<10 \%$ showed $\mathrm{I}^{2}$ values of $56.1 \%(\mathrm{p}=0.131)$ and $56.5 \%(p=0.129)$, respectively, and suggested high heterogeneity (Figure 3A \& 3B).

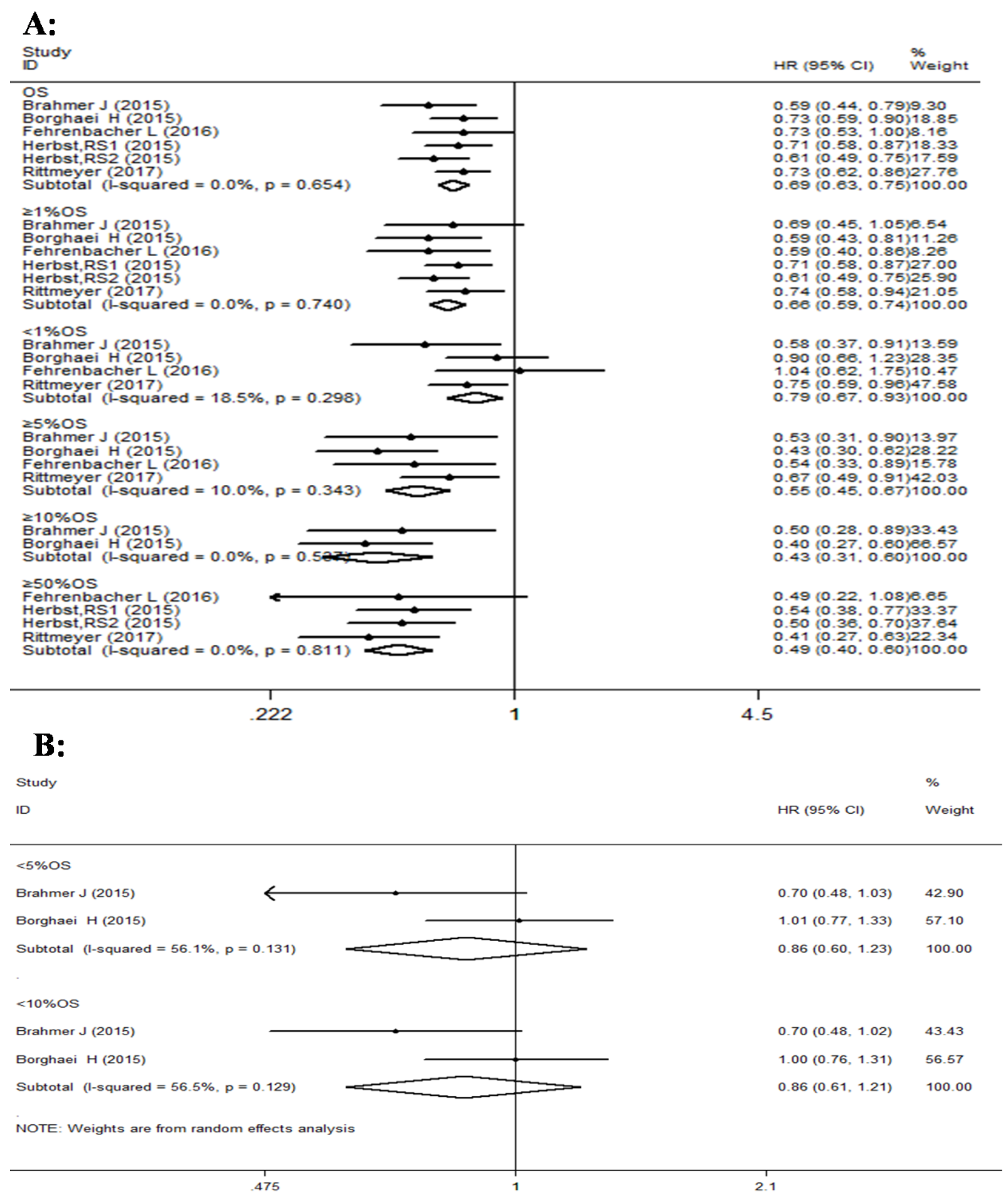

Figure 3: Forest plot analysis for OS between patients treated with PD-1/PD-L1 antibodies and docetaxel monotherapy along with different levels of PD-L1 expression. A. (I-squared $<50 \%$, FEM): All patients, PD-L1 $\geq 1 \%$, PD-L1 < $1 \%$, PD-L1 $\geq 5 \%$, PD-L1 $\geq 10 \%$, PD-L1 $\geq 50 \%$; B. ( I-squared $\geq 50 \%$, RAM): PD-L $1<5 \%$, PD-L $1<10 \%$ 
Table 3: Evaluation of publication bias with Begg's test and Egger's test

\begin{tabular}{|c|c|c|c|c|c|c|c|c|}
\hline & \multirow{2}{*}{ trails } & \multicolumn{2}{|c|}{ Heterogeneity } & \multirow{2}{*}{ HR/RR $(95 \% C I)$} & \multicolumn{2}{|c|}{ Begg's test } & \multicolumn{2}{|c|}{ Egger's test } \\
\hline & & $P$ & $I^{2}$ & & $\mathbf{Z}$ & $P$ & $T$ & $P$ \\
\hline OS & 5 & 0.654 & $0.0 \%$ & $0.69(0.63,0.75)$ & 1.13 & 0.26 & -0.89 & 0.422 \\
\hline PFS & 5 & 0.103 & $45.0 \%$ & $0.87(0.80,0.94)$ & 1.13 & 0.26 & -1.34 & 0.252 \\
\hline ORR & 5 & 0.032 & $59.0 \%$ & $1.53(1.16,2.01)$ & 1.32 & 0.19 & 0.66 & 0.546 \\
\hline AEs(G1-4) & 5 & 0.421 & $0.4 \%$ & $0.77(0.74,0.80)$ & 0.75 & 0.45 & -0.60 & 0.582 \\
\hline $\operatorname{AEs}(G 3-4)$ & 5 & 0.000 & $91.0 \%$ & $0.33(0.22,0.51)$ & 0.75 & 0.45 & -0.82 & 0.458 \\
\hline
\end{tabular}

\section{Progression free survival analysis}

Similarly, forest plot analysis of PFS indicated better results with PD-1/PD-L1 antibodies than docetaxel in advanced NSCLC patients (Figure 4). The PD-1/PD-L1 antibodies displayed significant improvement in PFS of advanced NSCLC patients, with HR value of 0.87 (95\% CI: 0.80-0.94; $\mathrm{p}<0.001)$. The subgroup analysis for PFS based on PD-L1 expression also showed statistically significant improvement in some subgroups with PD-1 antibody treatment over docetaxel. The pooled HR values of subgroups with PD-L1 expression of $\geq 1 \%, 5 \%, 10 \%$ and $50 \%$ were 0.83 (95\% CI: $0.75-0.91, p=0.000) ; 0.65$ (95\% CI: 0.55-0.79, p < 0.001); 0.54 (95\% CI: 0.40-0.72, p < 0.001); and 0.59 (95\% CI: 0.51-0.71, p < 0.001), respectively. However, the pooled HR values of subgroups with PD-L1 expression of $<1 \%,<5 \%$ and $<10 \%$ were 1.00 (95\% CI: 0.86-1.17, $\mathrm{p}=0.968)$; 1.01 (95\% CI: 0.58 $1.74, \mathrm{p}=0.982)$; and 0.94 (95\% CI: 0.54-1.65, $\mathrm{p}=0.839$ ), respectively, and did not show statistically significant improvement. Overall, there was some heterogeneity for PFS in all studies $\left(\mathrm{I}^{2}=45.4 \%, \mathrm{p}=0.103\right)$. The subgroup analysis for PFS based on PD-L1 expression showed different levels of heterogeneity, ranging from no to significant levels. For instance, PD-L1 expression with $\geq 1 \%, 5 \%, 10 \%, 50 \%$ and $<1 \%$ showed $\mathrm{I}^{2}$ values of $0 \%$ $(\mathrm{p}=0.567) ; 6.2 \%(\mathrm{p}=0.362) ; 0 \%(\mathrm{p}=0.748) ; 0 \%(\mathrm{p}$ $=0.993)$ and $42.8 \%(\mathrm{p}=0.155)$, respectively. But PFS analysis of PD-L1 subgroups with expression $<5 \%$ and $<$ $10 \%$ showed $\mathrm{I}^{2}$ values of $83 \%(\mathrm{p}=0.015)$ and $84.8 \%(\mathrm{p}=$ 0.010 ), respectively, and represented high heterogeneity.

\section{ORR analysis}

The comparison of overall response rate in all four RCTs also demonstrated that PD-1/PD-L1 antibodies have significantly better effect than docetaxel (Figure 5). The ORR analysis which was done using fixed effects model due to very little heterogeneity between the different trials, except overall RR value of 1.53 , (95\% CI: 1.16-2.01, P $=0.003 ; \mathrm{I}^{2}=59.2 \%$ ) in favor of PD-1/PD-L1 antibodies in NSCLC patients. Further subgroup analysis of ORR according to PD-L1 expression also indicated that the pooled RRs in subgroups were in favor of PD-1 antibodies treatment. For example subgroups displaying PD-L1 expression of $\geq 1 \%, 5 \%, 10 \%$ and $50 \%$ had $R R$ values of 1.70 (95\% CI: 1.40-2.07, p < 0.001); 2.08 (95\% CI: 1.45 2.97, $\mathrm{p}<0.001) ; 2.75$ (95\% CI: 1.56-4.87, $\mathrm{p}=0.001)$; and 3.55 (95\% CI: 2.48-5.08, p < 0.001), respectively. However, the pooled RRs of subgroups with PD-L1 expression of $<1 \%,<5 \%$ and $<10 \%$ were $0.81(95 \% \mathrm{CI}$ : $0.53-1.22, \mathrm{p}=0.305) ; 0.79(95 \%$ CI: 0.57-1.12, $\mathrm{p}=0.196)$; and 1.01 (95\% CI: 0.62-1.64, p $=0.978)$, respectively, and were not statistically significant. The heterogeneity among other subgroups except overall RR was between 0 to $50 \%$ and was thus not a major factor effecting RR values.

\section{Adverse events analysis}

As compared with standard second line docetaxel chemotherapy, the advanced stage NSCLC patients receiving PD-1/PD-L1 antibodies showed significant increase in the incidence rate of grade 1-4 adverse events (AEs). The overall $\mathrm{RR}$ value for $\mathrm{AE}$ was 0.77 (95\% CI: $0.74-0.79 ; \mathrm{P}=0.000)$, and specific $\mathrm{RRs}$ based on each event also showed significant effect, like for rashes, the $\mathrm{RR}$ value was $2.01,95 \% \mathrm{CI}$ : $1.14-3.51, \mathrm{P}=0.02$; for hypothyroidism, the RR value was $23.36,95 \%$ CI: $8.04-$ 67.90; $\mathrm{P}<0.001$; for hyperthyroidism, the RR value was 5.1, 95\% CI: 2.23-11.68, $\mathrm{P}<0.001$; for pneumonitis, the RR value was 3.19, 95\% CI: 1.9-5.34, $\mathrm{P}<0.001$; and for colitis, the RR value was $4.99,95 \% \mathrm{CI}: 1.45-17.11, \mathrm{P}=$ 0.011 . But, we did not observe any significant difference for the incidence rate of interstitial lung disease between both groups (Table 2). However, compared with docetaxel, the patients receiving PD-1/PD-L1 antibodies showed significant decrease in the incidence rate of grade 1-4 AEs such as nausea, febrile neutropenia, diarrhea, anemia, neutropenia, fatigue and alopecia (nausea: RR 0.58, 95\% CI: 0.46-0.75, P < 0.001; febrile neutropenia: RR 0.02, 95\% CI: 0.01-0.06, P<0.001; diarrhea: RR 0.41, 95\% CI: 0.31-0.55; neutropenia: RR 0.04, 95\% CI: $0.02-0.10, \mathrm{P}<$ 0.001; anemia: RR $0.25,95 \%$ CI: $0.14-0.42, \mathrm{P}<0.001$; fatigue: RR $0.63,95 \%$ CI: $0.56-0.71, \mathrm{P}<0.001$; alopecia: RR 0.02, 95\% CI: 0.01-0.04, P $<0.001$ ).

In addition we also compared the grade 3-4 adverse events between PD-1/PD-L1 antibody and docetaxel alone treatment arms. The patients receiving PD-1/PD- 


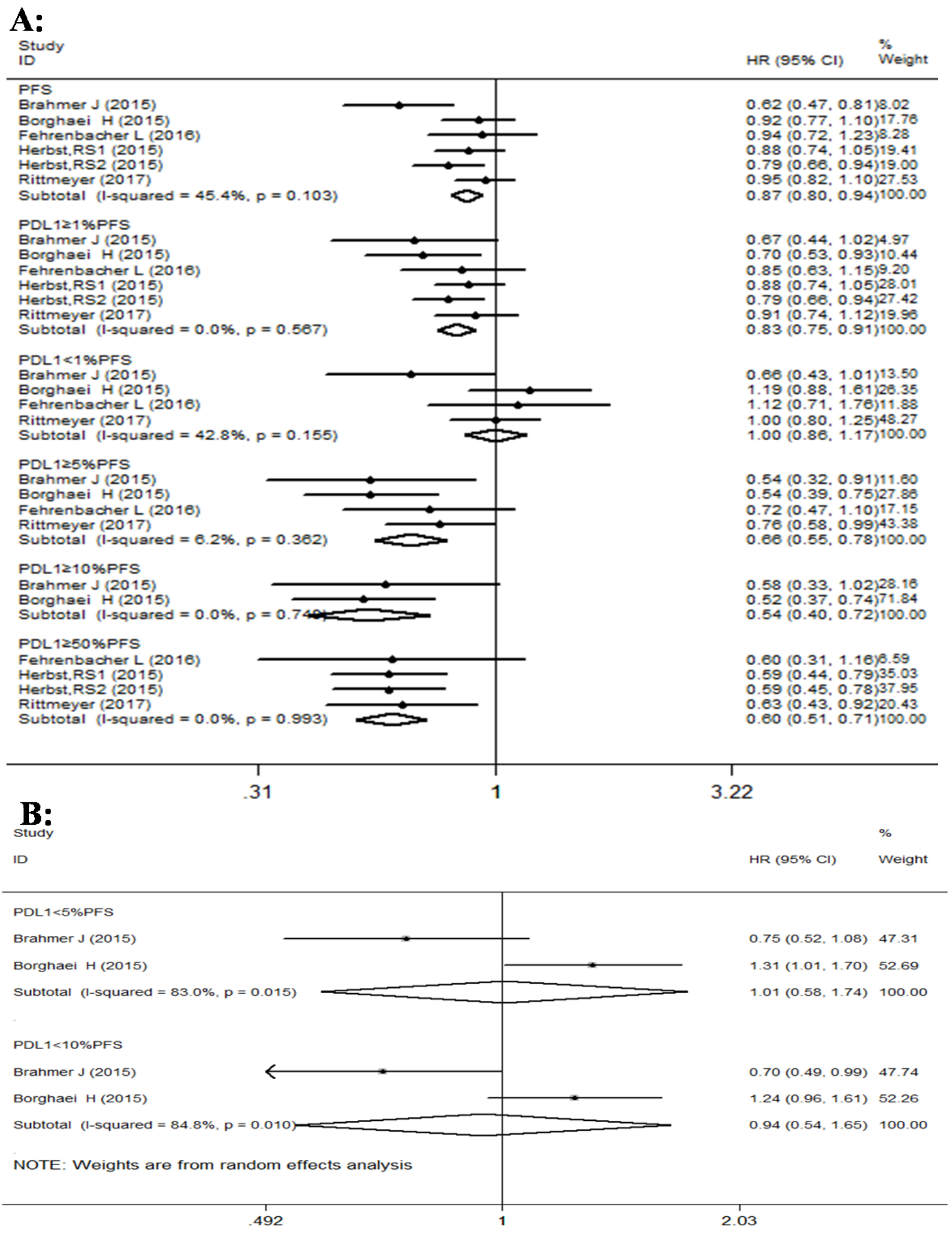

Figure 4: Forest plot analysis for PFS between patients treated with PD-1/PD-L1 antibodies and docetaxel monotherapy along with different levels of PD-L1 expression. A. (I-squared $<50 \%$, FEM): All patients, PD-L1 $\geq 1 \%$, PD-L $1 \geq 5 \%$, PD-L $1 \geq 10 \%$, PD-L $1 \geq 50 \%$. B. ( I-squared $\geq 50 \%$, REM): PD-L $1<1 \%$, PD-L $1<5 \%$, PD-L $1<10 \%$. 
L1 antibodies showed significant decrease in grade 3-4 AEs with overall RR value of 0.33 ; 95\% CI: 0.22-0.51, $\mathrm{P}<0.001$. Specifically febrile neutropenia, diarrhea, neutropenia, anemia and fatigue displayed following RR values(febrile neutropenia: RR 0.02, 95\% CI: 0.01 0.07, P < 0.001; diarrhea: RR 0.26, 95\% CI: 0.13-0.52; neutropenia: RR 0.02, 95\% CI: 0.01-0.05, P < 0.001; anemia: RR 0.34, 95\% CI: 0.20-0.56, P < 0.001; fatigue: RR 0.42, 95\% CI: 0.28-0.63, P < 0.001; alopecia: RR 0.25, 95\% CI: 0.06-0.99, $\mathrm{P}=0.048)$. However the incidence rates of other grade 3-4 AEs including: nausea, rash and colitis, did not show any significant difference between PD-1 antibodies and docetaxel therapy (Table 2).

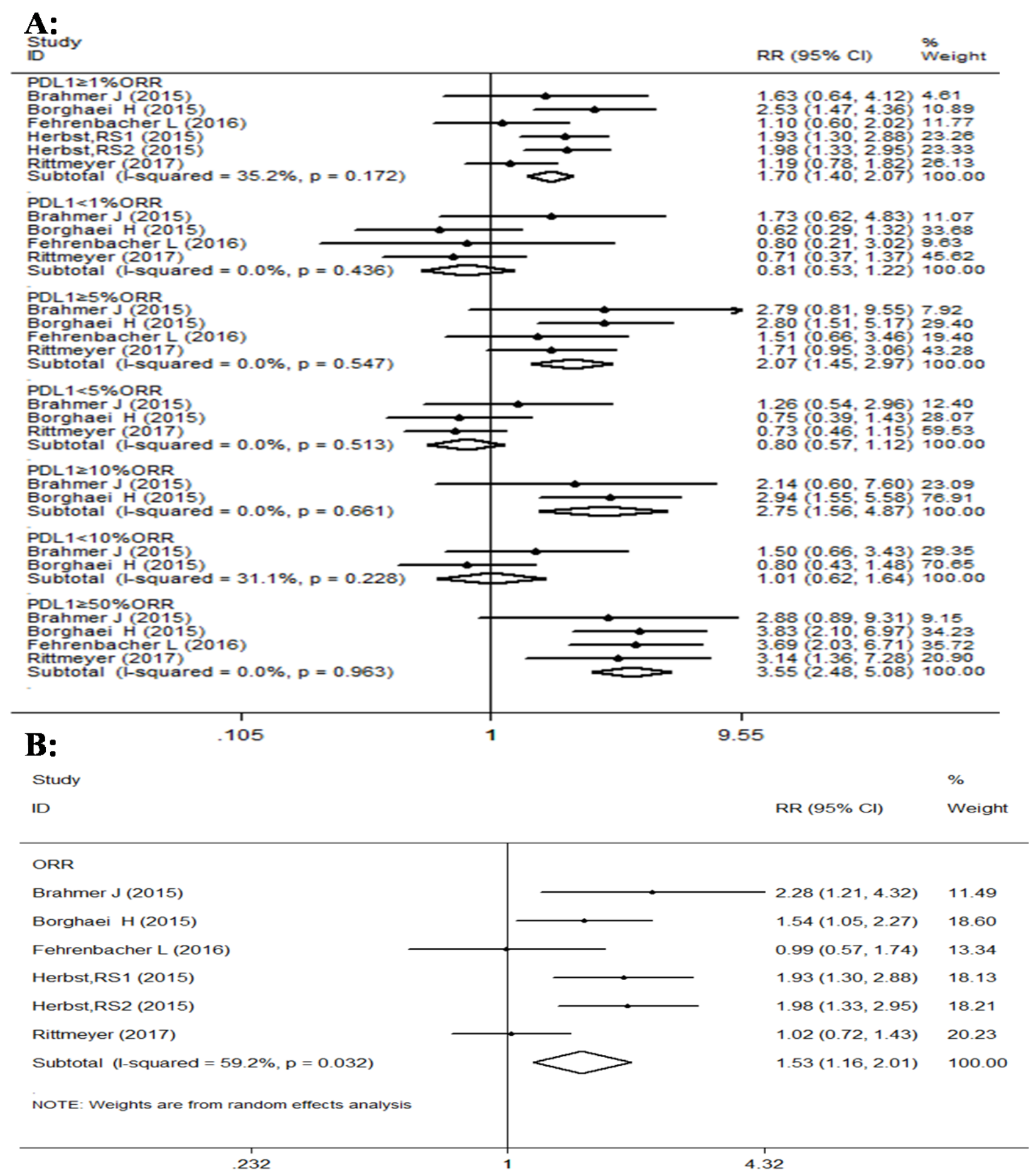

Figure 5: Forest plot analysis for ORR between patients treated with PD-1/PD-L1 antibodies and docetaxel

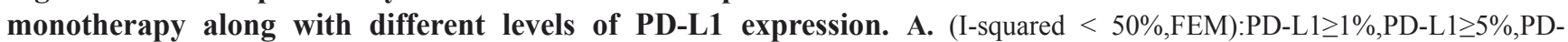
$\mathrm{L} 1 \geq 10 \%$,PD-L1 $\geq 50 \%$,PD-L1 < 1\%,PD-L1 < 5\%,PD-L1 < 10\%; B. ( I-squared $\geq 50 \%$, RAM): All patients. 


\section{Analysis of publication bias}

To evaluate the publication bias between different studies, STATA 12.0 software based Egger's test and Begg's test were utilized. The results have been presented in Table 3, and all P values were more than 0.05 after both tests, thereby, suggesting no significant publication bias in our meta-analysis.

\section{DISCUSSION}

PD-1 and PD-L1 molecules play an important role in limiting the tumor suppressive function of $\mathrm{T}$ cells. Upregulated PD-L1 on tumor cells binds to PD-1 on T cells, and turn off the immune surveillance. Consequently, tumor cells escape the body immune response against them and have unlimited growth [21]. Recently, the checkpoint inhibitors/antibodies, such as PD-1/PD-L1 antibodies have been observed to enhance the tumor suppressor activity of $\mathrm{T}$ immune cells in solid tumors including advanced NSCLC, and have shown very promising results in multiple cancers in many clinical trials. Herein, we have selected 5 RCTs including NSCLC patients to perform the meta-analysis to compare the efficacy of PD1/PD-L1 antibodies with docetaxel. These RCTs have alternatively been referred as CheckMate017, CheckMate057, KEYNOTE010, POPLAR and OAK [15-19]. Many additional clinical trials of PD-1/PD-L1 antibodies are also ongoing such as KEYNOTE-042 which intend to compare pembrolizumab as first-line therapy against platinum doublet chemotherapy for advanced NSCLC [22-24].

Our meta analysis showed that PD-1/PD-L1 antibodies treatment significantly improved the OS, PFS and ORR of advanced SQ- and NSQ-NSCLC patients as compared to docetaxel as second-line therapy. Moreover, the OS, PFS and ORR were significantly elevated with PD-1 or PD-L1 antibodies than docetaxel in subgroups with PD-L1 expression of $\geq 1 \%, 5 \%, 10 \%$ and $50 \%$. because subgroups with PD-L1 expression less than 5\%, $10 \%$ did not show significant differences. Thus, According to our meta analysis, we concluded that PD-L1 expression of $\geq 10 \%$ on tumor cells, can be a cutoff value for guiding the application of PD1/PDL1 antibodies therapy in NSCLC patients. As can be seen, PD-L1 expression of $\geq 50 \%$ on tumor cells has supported the application of PD1/PDL1 antibodies therapy in NSCLC patients.Latest NCCN 2017 of lung cancer also bring forword PD-L1 expression of $\geq 50 \%$ is a cutoff value for guiding the application ofPD1/PDL1 antibodies therapy in NSCLC patients in $1^{\text {st }}$ line. However, different studies have reported different PD-L1 cutoff values to be considered as PD-L1 positive $[25,26]$. Notably, membranous and/or cytoplasmic PD-L1 expression in lung cancer cells was assessed by immunohistochemistry (IHC) in CheckMate017, CheckMate057 and KEYNOTE010
RCTs $[15,16,18]$, but now some studies in various solid cancers have indicated that combined PD-L1 expression on tumor infiltrating lymphocytes and dendritic cells (TILs and TIDCs) in the cancer tumor microenvironment could be important [27-29]. In the RCTs analyzed in our study, the evaluation of PD-L1 expression appears more complex in two RCTs (POPLAR and OAK) than other 3 RCTs, because it considered PD-L1 expression from both tumor cells and infiltrating immune cells $[17,19]$.

Although PD-1/PD-L1 inhibitors/antibodies are a better treatment option, but due to their higher cost, they are less accessible to many patients. Thus identification of a markers which can enable the patients to figure out the possibility of effective treatment with these checkpoint inhibitors, would go a long way in helping them to invest their resources wisely. Regarding the costeffectiveness, it has been suggested that PD-L1 expression of $\geq 1 \%$ improved incremental quality-adjusted life-years (QALY) with nivolumab, for patients with NSQ tumors by $67 \%$, and led to $40 \%$ reduction in the incremental costeffectiveness ratios (ICER) (from US\$ $176 \mathrm{~K}$ to $105 \mathrm{~K})$. In case of pembrolizumab, the use of $50 \%$ instead of $1 \%$ cutoff, helped to increase the incremental QALY by $18 \%$ and reduced ICER by $15 \%$ (from US Dollar $163 \mathrm{~K}$ to 138K) [14]. Consistent with these suggestions, our analysis, showed that PD-L1expression cutoff of $10 \%$ was sufficient to display the advantage of choosing PD-1/PDL1 antibody therapy in NSCLC over standard second line chemotherapy, docetaxel.

However,in our meta, the OS of the patients was significantly elevated with PD-1/PD-L1 antibodies than docetaxel in subgroups with PD-L1 expression of $<1 \%$, which is consistant with the rusults of several some studies [30-32]. Brahmer [15] did not suggest PD-L1 expression as an effective biomarker of selecting patients for PD-1/ PD-L antibody therapy, especially when those with tumors lacking PD-L1 expression (PD-L1 < 1\%) has also been observed to derive benefit from PD-1/PD-L1 antibodies in advanced NSCLC. In fact, there exist several challenges in using PD-L1 expression as a powerful indicator for choosing the PD/PDL therapy. Firstly, the expression of PD-L1 shows much heterogeneity of an individual, which might reflects the heterogenous expression of PD-L1 among cancerous cells in the primary tumor, the differenc of PD-L1 expression between the primary lesion and its metastases, and finally, the difference of PD-L1 expression of the tumor and its surrounding stoma cells, especially inflammatory cells such as lymphocytes and macrophages [33-36]. Secondly, PD-L1 also manifests dynamic, but not static expression manner in the patients, which, for example, can be induced by activated tumorspecific T cells $[34,37]$. Thirdly, immunohistochemistry is the mostly employed to determine the positivity of the expression of PD-L1, which could be confined by the availablity and efficency of its current commercial anibodies. At least, 5 antibodies, Dako 28-8, Dako 22C3, 
Roche ventana, SP142 and SP263 are used in the clinical trials for PD-1/PD-L1therapy [38]. How to understand and bridge the divergence of the positive rate determined by different antibodies constitutes a technical chanllenge for pathologists. Now, A more accurate, quantificable and objective method for determining the PD-L1 positive rate is in urgent need in clinic, where those such as examination of PD-L1 positive circulating tumor cells with flow cytometry and mismatch-repair deficiency(MMR) hold promise $[39,40]$.

The adverse events due to immunotherapy have been because of disruption in immune tolerance. The immune-related adverse events (irAEs) are usually defined as any AE associated with drug exposure and consistent with an immune-mediated mechanism of action [41, 42]. Our analysis indicated that anti PD-1 therapy is associated with fewer adverse events than docetaxel treatment, which is in accordance with previous reports about grade 1-4 nausea, febrile neutropenia, diarrhea, anemia, neutropenia, fatigue and alopecia. Endocrinopathies are perhaps the most elusive irAEs, due to their nonspecific presentations. Among these, thyroid changes (mostly hypothyroidism) are the most common endocrine events, reported in about $3 \%-6 \%$ of NSCLC patients treated with PD-1 checkpoint inhibitors. Hypothyroidism can still be found in asymptomatic patient, and this could involve elevated levels of thyroid-stimulating hormone (TSH) or even without it. In addition, presentations of hypothyroidism, hyperthyroidism and pneumonitis due to PD-1/PD-L1 antibodies are 23.36, 5.10 and 3.19 folds higher than docetaxel group $(\mathrm{P}<0.001)$. The off-target effects against the normal lung parenchyma could be a result of increased immune response against the tumor by PD-1inhibition. Although, anti-PD-1 drugs rarely caused pneumonitis (any grade $4-6 \%$, grade 3-4: 0-2\%), but pneumonitis has significant potential for morbidity and mortality, and thus, occurence of it should be approached with caution. Similar to fatal pneumonitis, interstitial lung disease (ILD) have also been represented in advanced NSCLC patients treated with EGFR-TKIs (gefitinib: 3.5\%; erlotinib: about $1.6 \%-4.5 \%)[43,44]$ and with chemotherapy (docetaxel: $4.6 \%$; gemcitabine: $<1 \%$ ) [45-47]. In recent years, there has been reports about docetaxel-related interstitial lung disease (ILD), where ILD onset occurred 10-20 days (median time: 18 days) after docetaxel administration [48, 49]. However, in our meta-analysis, we did not find any difference in ILD between patients treated with PD-1/PDL1 antibodies or docetaxel.

Thus, in conclusion, our meta-analysis study indicated that PD-1/PD-L1 antibodies treatment indeed has beneficial effects on advanced NSCLC patients in comparison to docetaxel monotherapy, along with displaying few adverse events. In addition, the PD-L1 expression of more than $10 \%$ on tumor tissues can serve as a biomarker to identify the NSCLC patient populations that might respond positively to PD-1/ PD-L1 antibody therapy, and thereby helping many patients to make a informed decision about this high cost immunotherapy.

\section{MATERIALS AND METHODS}

\section{Search strategy}

All the random controlled trials with information about NSCLC, docetaxel, PD1 and PD-L1 antibodies, from January 1990 to January 2017, were searched using the following databases, Cochrane library, Embase, PubMed, China hospital knowledge database, China National Knowledge Infrastructure, Wangfang Data and Weipu Data. The medical subject heading (MeSH) terms included for searching the relevant studies were: lung neoplasm, pulmonary neoplasm, lung carcinoma, pulmonary carcinoma, lung cancer, pulmonary cancer and PD-1 or PD-L1, PD-1 or PD-L1 inhibitors and chemotherapy or docetaxel.

\section{Inclusion critera}

The studies with the following information were selected for inclusion in our meta-analysis; (1) Phase II/ III (randomized controlled trails) RCTs with primary endpoints as OS or PFS; (2) histological confirmed SQ and/or NSQ non small cell lung cancer; (3) having the information about OS, PFS and ORR, AEs, and PD-L1 expression; (4) published in English language; and (5) having some similarity between experimental design and methods across different studies. However, the studies were excluded if they were: (1) reviews, duplicate reports, letters, unfinished studies, or conference reports; (2) studies conducted with cell lines, animal models or other types of non-lung cancers; (3) studies where HR and 95\% CI could not be determined due to insufficient survival data; (4) papers in other laungages except English; (5) methods or experimental design were substantially different from other selected RCTs; and (6) sample size was smaller than 100 .

\section{Data extraction}

Two reviewers (Qiang $\mathrm{Su}$ and Yanli Hou) independently searched all the relevant studies and read the titles, abstracts and full texts of the identified studies. Cases of disagreement were resolved through discussion with the third reviewer (Chenguang Zhang). The following information was extracted from the selected studies; year of publication, name of the journal, author's name, methods of randomization, OS, PFS, ORR, PD-L1 expression rate and adverse events (AEs) with grades 1-4 and $3 / 4$. 


\section{Data analysis}

In our meta-analysis, Risk of bias analysis was prepared using Review Manager 5.3 software (Cochrane Collaboration 2014,Nordic Cochrane Center,Copenhagen,Denmark).Two reviewers (Q.S.and C.G.Z.) independently assessed the quality of the included studies according to the Cochrane risk of bias tool, which assesses the following six domains: selection bias (including both "Random sequence generation" and "allocation concealment"), performance bias, detection bias, attrition bias, reporting bias and other bias. The Stata version 12.0 statistical software (Stata Corporation, College Station, Texas, USA) was used to conduct the meta-analysis. The HR and 95\% CI values were collected and merged to estimate overall OS and PFS. The HR value of $<1.0$ indicated reduced progression or death in the PD-1/PD-L1 antibody group. The RR value was used to estimate ORR and AEs for grade 1-4/3-4, and RR value of $>1.0$ represented higher ORR or the incidence of grade 1-4 and 3/4 AEs in the PD-1/PD-L1 antibodies group. In addition, the Cochran's $\chi 2$ test was used to assess the heterogeneity among the RCTs. When $\mathrm{I}^{2}$ value was $<50 \%$, the fixed-effects model (FEM) was employed for analysis, and if $\mathrm{I}^{2}$ value was $\geq 50 \%$, random-effects model (REM) was used. The Begg's and Egger's tests were used to analyze the publication bias between different RCTs.

\section{Author Contributions}

B.W.C., Q.S.and Y.L.H. had entire access to all the data included in the study and takes duty for the completeness of the data and the accuracy of our analysis. Z.G.S. helped the design of the study, and C.G. $Z$. contributed to the statistical analysis and the revision of this manuscript.Q.S. and C.G. Z.approved the final manuscript.

\section{ACKNOWLEDGMENTS}

This work was funded through the National Nature Science Foundation of China (No.81272615, to Bangwei Cao); the Foundation clinical research of Capital Medical University (No.15JL33); the Foundation of Beijing friendship hospital (yyqdkt 2014-12).

\section{CONFLICTS OF INTEREST}

The authors declare no conflicts of interest in preparing this article.

\section{REFERENCES}

1. SEER. Cancer Stat Fact Sheets: Lung and Bronchus Cancer. http://seer.cancer.gov/statfacts/html/lungb.html. 2015.

2. Siegel RL, Miller KD, Jemal A. Cancer statistics, 2016. CA Cancer J Clin. 2016; 66: 7-30.

3. Chen W, Zheng R, Baade PD, Zhang S, Zeng H, Bray F, Jemal A, Yu XQ, He J. Cancer statistics in China, 2015. CA Cancer J Clin. 2016; 66: 115-32.

4. Devarakonda S, Morgensztern D, Govindan R. Genomic alterations in lung adenocarcinoma. Lancet Oncol. 2015; 16: e342-51.

5. Herbst RS, Heymach JV, Lippman SM. Lung cancer. N Engl J Med. 2008; 359:1367-80.

6. Fossella FV, DeVore R, Kerr RN, Crawford J, Natale RR, Dunphy F, Kalman L, Miller V, Lee JS, Moore M, Gandara D, Karp D, Vokes E, et al. Randomized phase III trial of docetaxel versus vinorelbine or ifosfamide in patients with advanced non-small-cell lung cancer previously treated with platinum-containing chemotherapy regimens. The TAX 320 Non-Small Cell Lung Cancer Study Group. J Clin Oncol. 2000; 18: 2354-62.

7. Lindeman NI, Cagle PT, Beasley MB, Chitale DA, Dacic S, Giaccone G, Jenkins RB, Kwiatkowski DJ, Saldivar JS, Squire J, Thunnissen E, Ladanyi M. Molecular testing guideline for selection of lung cancer patients for EGFR and ALK tyrosine kinase inhibitors: guideline from the College of American Pathologists, International Association for the Study of Lung Cancer, and Association for Molecular Pathology. Arch Pathol Lab Med. 2013; 137: 828-60.

8. Shepherd FA, Dancey J, Ramlau R, Mattson K, Gralla R, O'Rourke M, Levitan N, Gressot L, Vincent M, Burkes R, Coughlin S, Kim Y, Berille J. Prospective randomized trial of docetaxel versus best supportive care in patients with non-small-cell lung cancer previously treated with platinum-based chemotherapy. J Clin Oncol. 2000; 18: 2095-103.

9. Momtaz P, Postow MA. Immunologic checkpoints in cancer therapy: focus on the programmed death-1 (PD-1) receptor pathway. Pharmgenomics Pers Med. 2014; 7:35765.

10. Pardoll DM. The blockade of immune checkpoints in cancer immunotherapy. Nat Rev Cancer. 2012; 12: 252-64.

11. Melosky B, Chu Q, Juergens R, Leighl N, McLeod D, Hirsh V. Pointed Progress in Second-Line Advanced NonSmall-Cell Lung Cancer: The Rapidly Evolving Field of Checkpoint Inhibition. J Clin Oncol. 2016; 34: 1676-88.

12. Kazandjian D, Suzman DL, Blumenthal G, Mushti S, He K, Libeg M, Keegan P, Pazdur R. FDA Approval Summary: Nivolumab for the Treatment of Metastatic Non-Small Cell Lung Cancer With Progression On or After Platinum-Based Chemotherapy. Oncologist. 2016; 21: 634-42.

13. US Food and Drug Administration. FDA approves Keytruda for advanced non-small cell lung cancer: First drug approved in lung cancer for patients whose tumors express PD-L1. http://www.fda.gov/NewsEvents/Newsroom/ PressAnnouncements/ucm465444.htm. 2015. 
14. Aguiar P, De Mello R, Tadokoro H, Santoro I, Babiker H, Avancha K, Gutierres B, Barreto C, Lopes G. O.03: Cost Effectiveness of Immune Checkpoint Inhibitors in NonSmall Cell Lung Cancer Relative to PD-L1 Expression. J Thorac Oncol. 2016; 11: S169-S170.

15. Brahmer J, Reckamp KL, Baas P, Crinò L, Eberhardt WE, Poddubskaya E, Antonia S, Pluzanski A, Vokes EE, Holgado E, Waterhouse D, Ready N, Gainor J, et al. Nivolumab versus Docetaxel in Advanced Squamous-Cell Non-Small-Cell Lung Cancer. N Engl J Med. 2015; 373: 123-35.

16. Borghaei H, Paz-Ares L, Horn L, Spigel DR, Steins M, Ready NE, Chow LQ, Vokes EE, Felip E, Holgado E, Barlesi F, Kohlhaufl M, Arrieta O, et al. Nivolumab versus Docetaxel in Advanced Nonsquamous Non-Small-Cell Lung Cancer. N Engl J Med. 2015; 373: 1627-39.

17. Fehrenbacher L, Spira A, Ballinger M, Kowanetz M, Vansteenkiste J, Mazieres J, Park K, Smith D, ArtalCortes A, Lewanski C, Braiteh F, Waterkamp D, He P, et al. Atezolizumab versus docetaxel for patients with previously treated non-small-cell lung cancer (POPLAR): a multicentre, open-label, phase 2 randomised controlled trial. Lancet. 2016; 387: 1837-46.

18. Herbst RS, Baas P, Kim DW, Felip E, Pérez-Gracia JL, Han JY, Molina J, Kim JH, Arvis CD, Ahn MJ, Majem M, Fidler MJ, de Castro G, et al. Pembrolizumab versus docetaxel for previously treated, PD-L1-positive, advanced non-small-cell lung cancer (KEYNOTE-010): a randomised controlled trial. Lancet. 2016; 387: 1540-50.

19. Rittmeyer A, Barlesi F, Waterkamp D, Park K, Ciardiello F, von Pawel J, Gadgeel SM, Hida T, Kowalski DM, Dols $\mathrm{MC}$, Cortinovis DL, Leach J, Polikoff J, et al. Atezolizumab versus docetaxel in patients with previously treated nonsmall-cell lung cancer (OAK): a phase 3, open-label, multicentre randomised controlled trial. Lancet. 2017; 389: 255-65.

20. Abdel-Rahman O. Correlation between PD-L1 expression and outcome of NSCLC patients treated with anti-PD-1/PDL1 agents: A meta-analysis. Crit Rev Oncol Hematol. 2016; 101: 75-85.

21. Sgambato A, Casaluce F, Sacco PC, Palazzolo G, Maione P, Rossi A, Ciardiello F, Gridelli C. Anti PD-1 and PDL-1 Immunotherapy in the Treatment of Advanced Non- Small Cell Lung Cancer (NSCLC): A Review on Toxicity Profile and its Management. Curr Drug Saf. 2016; 11: 62-8.

22. Gridelli C, Besse B, Brahmer JR, Crinò L, Felip E, de Marinis F. The Evolving Role of Nivolumab in NonSmall-Cell Lung Cancer for Second-Line Treatment: A New Cornerstone for Our Treatment Algorithms. Results From an International Experts Panel Meeting of the Italian Association of Thoracic Oncology. Clin Lung Cancer. 2016; 17: 161-8.

23. Tony Mok, Yi-Long $\mathrm{Wu}$, Patricia A, Watson, Jin Zhang, Reshma A. Rangwala, Gilberto Lopes.Phase 3 KEYNOTE-042 trial of pembrolizumab (MK-3475) versus platinum doublet chemotherapy in treatment-naive patients (pts) with PD-L1-positive advanced non-small cell lung cancer (NSCLC).2015.http://meetinglibrary.asco.org/ content/147431-156.

24. Sharon E, Streicher H, Goncalves P, Chen HX. Immune checkpoint inhibitors in clinical trials. Chin J Cancer. 2014; 33: 434-44.

25. Sacher AG, Gandhi L. Biomarkers for the Clinical Use of PD-1/PD-L1 Inhibitors in Non-Small-Cell Lung Cancer: A Review. JAMA Oncol. 2016; 2:1217-22.

26. Mino-Kenudson M. Programmed cell death ligand-1 (PDL1) expression by immunohistochemistry: could it be predictive and/or prognostic in non-small cell lung cancer. Cancer Biol Med. 2016; 13: 157-70.

27. Taube JM, Klein A, Brahmer JR, Xu H, Pan X, Kim JH, Chen L, Pardoll DM, Topalian SL, Anders RA. Association of PD-1, PD-1 ligands, and other features of the tumor immune microenvironment with response to anti-PD-1 therapy. Clin Cancer Res. 2014; 20: 5064-74.

28. Velcheti V, Schalper KA, Carvajal DE, Anagnostou VK, Syrigos KN, Sznol M, Herbst RS, Gettinger SN, Chen L, Rimm DL. Programmed death ligand-1 expression in nonsmall cell lung cancer. Lab Invest. 2014; 94: 107-16.

29. Kim MY, Koh J, Kim S, Go H, Jeon YK, Chung DH. Clinicopathological analysis of PD-L1 and PD-L2 expression in pulmonary squamous cell carcinoma: Comparison with tumor-infiltrating T cells and the status of oncogenic drivers. Lung Cancer. 2015; 88: 24-33.

30. Garon EB, Rizvi NA, Hui R, Leighl N, Balmanoukian AS, Eder JP, Patnaik A, Aggarwal C, Gubens M, Horn L, Carcereny E, Ahn MJ, Felip E, et al. Pembrolizumab for the treatment of non-small-cell lung cancer. N Engl J Med. 2015; 372: 2018-28.

31. Weber JS, Kudchadkar RR, Yu B, Gallenstein D, Horak CE, Inzunza HD, Zhao X, Martinez AJ, Wang W, Gibney G, Kroeger J, Eysmans C, Sarnaik AA, Chen YA. Safety, efficacy, and biomarkers of nivolumab with vaccine in ipilimumab-refractory or -naive melanoma. J Clin Oncol. 2013; 31: 4311-8.

32. Motzer RJ, Rini BI, McDermott DF, Redman BG, Kuzel TM, Harrison MR, Vaishampayan UN, Drabkin HA, George S, Logan TF, Margolin KA, Plimack ER, Lambert AM, et al. Nivolumab for Metastatic Renal Cell Carcinoma: Results of a Randomized Phase II Trial. J Clin Oncol. 2015; 33: 1430-7.

33. Topalian SL, Hodi FS, Brahmer JR, Gettinger SN, Smith DC, McDermott DF, Powderly JD, Carvajal RD, Sosman JA, Atkins MB, Leming PD, Spigel DR, Antonia SJ, et al. Safety, activity, and immune correlates of anti-PD-1 antibody in cancer. N Engl J Med. 2012; 366: 2443-54.

34. Meng X, Huang Z, Teng F, Xing L, Yu J. Predictive biomarkers in PD-1/PD-L1 checkpoint blockade immunotherapy. Cancer Treat Rev. 2015; 41:868-76.

35. Madore J, Vilain RE, Menzies AM, Kakavand H, Wilmott 
JS, Hyman J, Yearley JH, Kefford RF, Thompson JF, Long GV, Hersey P, Scolyer RA. PD-L1 expression in melanoma shows marked heterogeneity within and between patients: implications for anti-PD-1/PD-L1 clinical trials. Pigment Cell Melanoma Res. 2015;28: 245-53.

36. Tumeh PC, Harview CL, Yearley JH, Shintaku IP, Taylor EJ, Robert L, Chmielowski B, Spasic M, Henry G, Ciobanu V, West AN, Carmona M, Kivork C, et al. PD-1 blockade induces responses by inhibiting adaptive immune resistance. Nature. 2014; 515: 568-71.

37. Taube JM, Anders RA, Young GD, Xu H, Sharma R, McMiller TL, Chen S, Klein AP, Pardoll DM, Topalian SL, Chen L. Colocalization of inflammatory response with B7-h1 expression in human melanocytic lesions supports an adaptive resistance mechanism of immune escape. Sci Transl Med. 2012; 4: 127ra37.

38. Kerr KM, Tsao MS, Nicholson AG, Yatabe Y, Wistuba II, Hirsch FR. Programmed Death-Ligand 1 Immunohistochemistry in Lung Cancer: In what state is this art. J Thorac Oncol. 2015; 10: 985-9.

39. Nicolazzo C, Raimondi C, Mancini M, Caponnetto S, Gradilone A, Gandini O, Mastromartino M, Del Bene G, Prete A, Longo F, Cortesi E, Gazzaniga P. Monitoring PDL1 positive circulating tumor cells in non-small cell lung cancer patients treated with the PD-1 inhibitor Nivolumab. Sci Rep. 2016; 6: 31726.

40. Sloan EA, Ring KL, Willis BC, Modesitt SC, Mills AM. PD-L1 Expression in Mismatch Repair-deficient Endometrial Carcinomas, Including Lynch Syndromeassociated and MLH1 Promoter Hypermethylated Tumors. Am J Surg Pathol. 2017; 41: 326-33.

41. Garon EB. Current Perspectives in Immunotherapy for NonSmall Cell Lung Cancer. Semin Oncol. 2015; 42:S11-18.
42. Rizvi NA, Mazières J, Planchard D, Stinchcombe TE, Dy GK, Antonia SJ, Horn L, Lena H, Minenza E, Mennecier B, Otterson GA, Campos LT, Gandara DR, et al. Activity and safety of nivolumab, an anti-PD-1 immune checkpoint inhibitor, for patients with advanced, refractory squamous non-small-cell lung cancer (CheckMate 063): a phase 2, single-arm trial. Lancet Oncol. 2015; 16: 257-65.

43. Cohen MH, Williams GA, Sridhara R, Chen G, Pazdur R. FDA drug approval summary: gefitinib (ZD1839) (Iressa) tablets. Oncologist. 2003; 8: 303-6.

44. Min JH, Lee HY, Lim H, Ahn MJ, Park K, Chung MP, Lee KS. Drug-induced interstitial lung disease in tyrosine kinase inhibitor therapy for non-small cell lung cancer: a review on current insight. Cancer Chemother Pharmacol. 2011; 68: 1099-109.

45. Read WL, Mortimer JE, Picus J. Severe interstitial pneumonitis associated with docetaxel administration. Cancer. 2002; 94: 847-53.

46. Wang GS, Yang KY, Perng RP. Life-threatening hypersensitivity pneumonitis induced by docetaxel (taxotere). Br J Cancer. 2001; 85: 1247-50.

47. Sahin IH, Geyer AI, Kelly DW, O'Reilly EM. GemcitabineRelated Pneumonitis in Pancreas Adenocarcinoma-An Infrequent Event: Elucidation of Risk Factors and Management Implications. Clin Colorectal Cancer. 2016; 15: 24-31.

48. Abdel-Rahman O, Fouad M. Risk of pneumonitis in cancer patients treated with immune checkpoint inhibitors: a metaanalysis. Ther Adv Respir Dis. 2016; 10:183-93.

49. Wang CJ, Chang HT, Chang CY. Docetaxel-related interstitial pneumonitis. Ther Clin Risk Manag. 2015; 11: 1813-6. 